\title{
Controlling Flowering of Photoperiodic Ornamental Crops with Light-emitting Diode Lamps: A Coordinated Grower Trial
}

\author{
Qingwu Meng ${ }^{1}$ and Erik S. Runkle ${ }^{2}$
}

\begin{abstract}
ADDITIONAL INDEX WORDs. flowering lamp, LEDs, long days
SUMMARY. Photoperiodic lighting from lamps with a moderate ratio of red [R $(600$ $700 \mathrm{~nm})]$ to far-red [FR $(700-800 \mathrm{~nm})]$ light effectively promotes flowering of long-day plants (LDPs). Because of spectral controllability, long life span, and energy efficiency, light-emitting diodes (LEDs) have emerged as an alternative to conventional light sources, such as incandescent (INC) and high-pressure sodium (HPS) lamps. We conducted a coordinated trial with five commercial greenhouse growers to investigate the efficacy of $\mathrm{R}+$ white $(\mathrm{W})+$ FR LEDs, with an R:FR of 0.82 , to regulate flowering of daylength-sensitive ornamental crops. The trial was also performed in two replicate greenhouses at Michigan State University (MSU). Ageratum (Ageratum boustonianum), calibrachoa (Calibrachoa $\times$ bybrida), dahlia (Dablia $\times$ bybrida), dianthus (Dianthus chinensis), petunia (Petunia $\times$ bybrida), snapdragon (Antirrbinum majus), and verbena (Verbena $\times$ bybrida) were grown under natural short days (SDs) with 4-hour night-interruption (NI) lighting provided by the $\mathrm{R}+\mathrm{W}+$ FR LEDs or conventional lamps typically used by each grower. Two companies used HPS lamps, whereas the other sites used INC lamps. In addition, a natural SD treatment, a truncated 9-hour SD treatment, or a compact fluorescent lamp (CFL) NI treatment was provided at three different sites. With few exceptions, time to flower and flowering percentage of the bedding plant crops tested were similar under the $\mathrm{R}+\mathrm{W}+$ FR LEDs to that under the conventional lamps at all sites. At MSU, ageratum, dianthus, petunia, snapdragon, and verbena flowered earlier under NI lighting treatments than under 9-hour SDs. In addition, plant height and visible flower bud or inflorescence number at flowering were similar under the $\mathrm{R}+\mathrm{W}+\mathrm{FR}$ LEDs and INC lamps for most crops. Therefore, we conclude that the $\mathrm{R}+\mathrm{W}+\mathrm{FR}$ LEDs are as effective as lamps traditionally used in greenhouses at controlling flowering of photoperiodic plants.
\end{abstract}

M ost plants can be classified into one of three categories according to their photoperiodic responses: LDPs, short-day plants (SDPs), and day-neutral plants (Thomas and Vince-Prue, 1997). Flowering of LDPs is promoted when the night length is shorter than a species- or cultivar-specific critical dark period, whereas flowering of SDPs is inhibited or delayed when the uninterrupted dark period is shorter than a critical dark period (Thomas and Vince-Prue, 1997). When the ambient photoperiod

Department of Horticulture, 1066 Bogue Street, Michigan State University, East Lansing, MI 48824

We thank C. Raker \& Sons, the Center for Applied Horticultural Research at Altman Plants, Henry Mast Greenhouse, Krueger-Maddux Greenhouses, and Kube Pak for their cooperation with this project; Philips Lighting and HortAmericas for subsidizing the cost of the LEDs; the USDA National Institute of Food and Agriculture's Specialty Crop Research Initiative and Michigan State University's Project GREEEN for providing funding; and Mike Olrich for experimental assistance. This work was supported by the USDA National Institute of Food and Agriculture, Hatch project 192266

${ }^{1}$ Graduate Student

${ }^{2}$ Corresponding author. E-mail: runkleer@msu.edu. is short, low-intensity photoperiodic lighting can be used to control flowering of LDPs and SDPs. This can be achieved by delivering light beginning at the end of the day until the desired photoperiod is met (day extension) or during the middle of the night (night interruption). Although the minimum duration of effective NI lighting can vary among species, $4 \mathrm{~h}$ of NI lighting is typically sufficient to regulate flowering of photoperiodic crops (Runkle and Heins, 2003; Runkle et al., 1998). Generally, NI lighting is most effective when delivered during the middle of the long night. For example, to promote flowering of dianthus or inhibit flowering of 'Dream Land' zinnia (Zinnia elegans), 4-h NI lighting during a night lasting from 1700 to 0800 HR was most effective starting at 2200 $\mathrm{HR}$, rather than 1800 or $0200 \mathrm{HR}$ (Park et al., 2013).

Conventional light sources, such as INC, fluorescent (FL), and HPS lamps typically are used by commercial growers to deliver photoperiodic lighting. Incandescent lamps emit both $\mathrm{R}$ and FR light and are effective for a wide range of crops (Thomas and Vince-Prue, 1997). Because FL lamps emit little FR light, direct replacement of INC lamps with FL lamps delays flowering of some FRsensitive crops such as 'Wave Purple Classic' (WPC) petunia (Runkle et al., 2012). High-pressure sodium lamps, either fixed or with a rotating reflector, also promote flowering of LDPs and inhibit flowering of SDPs (Blanchard and Runkle, 2009, 2010; Whitman et al., 1998). High-pressure sodium lamps used for day-extension lighting to provide a 16 -h long day and INC lamps used for 4-h NI lighting following a 9-h SD were similarly effective at promoting flowering of four petunia species (Warner, 2010).

Light-emitting diodes have several technical advantages over conventional lamps. Conventional lamps emit a broad spectrum of light, and their spectral distribution cannot be easily modified. In contrast, LEDs emit photons of specific colors of light by blending different proportions of different elements. Therefore, LED lighting allows selection of the most efficacious spectral composition for specific plant responses (Heo et al., 2002; Schubert and Kim, 2005). Many conventional lamps generate a significant amount of undesired IR radiation, but LEDs emit little radiated heat and can be more energy efficient (Nelson and Bugbee, 2014; Pimputkar et al., 2009). The

\begin{tabular}{llll}
\hline $\begin{array}{l}\text { Units } \\
\begin{array}{l}\text { To convert U.S. to SI, } \\
\text { multiply by }\end{array}\end{array}$ & U.S. unit & SI unit & $\begin{array}{l}\text { To convert SI to U.S., } \\
\text { multiply by }\end{array}$ \\
\hline 29.5735 & $\mathrm{fl} \mathrm{oz}$ & $\mathrm{mL}$ & 0.0338 \\
0.3048 & $\mathrm{ft}$ & $\mathrm{m}$ & 3.2808 \\
0.0929 & $\mathrm{ft}^{2}$ & $\mathrm{~m}^{2}$ & 10.7639 \\
2.54 & inch $(\mathrm{es})$ & $\mathrm{cm}$ & 0.3937 \\
25.4 & inch $(\mathrm{es})$ & $\mathrm{mm}$ & 0.0394 \\
1 & $\mathrm{ppm}$ & $\mathrm{mg} \cdot \mathrm{L}^{-1}$ & 1 \\
$\left({ }^{\circ} \mathrm{F}-32\right) \div 1.8$ & ${ }^{\circ} \mathrm{F}$ & ${ }^{\circ} \mathrm{C}$ & $\left({ }^{\circ} \mathrm{C} \times 1.8\right)+32$
\end{tabular}


expected lifetime of a traditional INC lamp is $1000 \mathrm{~h}$, whereas that of a CFL lamp is between 8000 and 10,000 h (Tähkämö et al., 2012). In comparison, the useful lifetime of an LED lamp can be between 20,000 and $55,000 \mathrm{~h}$ when the lamp is operated at favorable temperatures (Morrow, 2008; Tähkämö et al., 2012).

The capability to use narrowband light from LEDs or to combine multiple wavebands has enabled researchers to determine the effects of light quality on flowering of a variety of crops without potentially confounding spectra. Light-emitting diodes with effective spectral composition can therefore replace conventional light sources. For example, LEDs emitting controlled amounts of blue [B (400$500 \mathrm{~nm})$ ], R, and FR light were a comparable alternative to HPS lamps at inducing flowering of ghent azalea (Rhododendron simsii), although the peak wavelengths of $B, R$, and FR light were not reported (Schamp et al., 2012). Flowering of the LDP cyclamen (Cyclamen persicum) was earlier under a mixture of R and B LEDs than FL lamps when used as NI lighting (Shin et al., 2010). In addition, LEDs with an $\mathrm{R}$ (peak wavelength $=660 \mathrm{~nm}$ ) to $\mathrm{FR}$ (peak wavelength $=735 \mathrm{~nm}$ ) light ratio (R:FR) of 0.66 or greater were as effective as INC lamps at inhibiting flowering of SDPs (Craig and Runkle, 2013). However, to our knowledge, studies on the efficacy of newly developed LEDs as an alternative to conventional lamp types on flowering applications have not been published.

Three commercial LED fixtures for photoperiodic lighting have been recently developed and marketed for potential flowering applications, emitting only $\mathrm{FR}, \mathrm{R}+\mathrm{W}$, or $\mathrm{R}+\mathrm{W}+$ FR. The 14-W R + W + FR LED lamp was developed as a commercial replacement for 100- to $150-W$ INC lamps to regulate flowering of ornamental crops. We coordinated a commercial greenhouse grower trial to investigate the efficacy of the $\mathrm{R}+\mathrm{W}+$ FR LED lamp to control flowering of daylength-sensitive plants compared with conventional lamps. Photoperiodic lighting with a mixture of $\mathrm{R}$ and FR light was most effective at promoting flowering of LDPs (Thomas and Vince-Prue, 1997), and LEDs with an R:FR of 0.66 or 1.07 were as effective as INC lamps at promoting flowering of LDPs and inhibiting flowering of SDPs (Craig and Runkle, 2012). Therefore, we postulated that the $\mathrm{R}+\mathrm{W}+\mathrm{FR}$ LED lamps with an $\mathrm{R}: F R$ of 0.82 would be as effective as conventional lamps at regulating flowering of photoperiodic crops.

\section{Materials and methods}

Plant material. All young plants were produced by a commercial plant producer [C. Raker \& Sons, Litchfield, MI (Raker)]. Seeds of 'Hawaii Blue' ageratum, 'Telstar Crimson' dianthus, 'Easy Wave Burgundy Star' (EWBS) and WPC petunia, 'Liberty Classic Yellow' snapdragon, and 'Obsession' verbena were sown into 288 -cell (6-mL) plug trays on 5 Jan. 2013, 4 Jan. 2013, 29 Dec. 2012, 28 Dec. 2012, 26 Dec. 2012, and 5 Jan. 2013, respectively. Cuttings of 'Callie Deep Yellow' calibrachoa and 'Dahlinova Texas' dahlia were stuck into 51-cell (27$\mathrm{mL}$ ) strip trays on 5 Jan. 2013 and 9 Jan. 2013, respectively. These eight crops were chosen according to their photoperiodic flowering responses. The typical commercial production period for these propagules was shortened by 1 week to ship plants before they could be induced to flower. The young plants were express shipped in late January to MSU (East Lansing) and to the five commercial growers cooperating in this experiment: Raker, the Center for Applied Horticultural Research at Altman Plants [Vista, CA (CfAHR)], Henry Mast Greenhouse [Byron Center, MI (Mast)], Krueger-Maddux Greenhouses [Sunman, IN (Krueger-Maddux)], and Kube Pak (Allentown, NJ). At MSU, this experiment was conducted as a randomized complete block design in two replicate greenhouses (houses 10E and 13B).

Upon receipt of the young plants, each site transplanted them into 18-cell (304-mL) trays (L-1801; Landmark Plastic Corp., Akron, OH) filled with their typical peat-based growing medium for bedding plant production, and four trays of each cultivar were placed under each lighting treatment described below. The dates of transplant and onset of treatments at Raker, CfAHR, KruegerMaddux, Kube Pak, and MSU were 1 Feb. 2013, 2 Feb. 2013, 28 Jan. 2013, 18 Feb. 2013, and 5 Feb. 2013, respectively. Before transplant, all plants at Kube Pak were grown under natural SDs $(\leq 10.8 \mathrm{~h})$. At Mast, plants were transplanted and transferred to an LED treatment on 1 Feb. 2013 and to an HPS treatment on 2 Feb. 2013 (see below). All plants were grown following the growers' standard production practices of watering, fertilization, and pest management. Application of plant growth retardants was also at the discretion of the grower, and if an application was made, it was the same for all treatments. At Raker, daminozide (B-Nine WSG; OHP, Mainland, PA) at 2500 ppm was applied as a foliar spray to dahlia, dianthus, and snapdragon on 13 Feb. 2013. At CfAHR, paclobutrazol (Bonzi; Syngenta, Greensboro, NC) was applied as a foliar spray at $14 \mathrm{ppm}$ to EWBS and WPC petunia and at 7 ppm to snapdragon; daminozide at $3200 \mathrm{ppm}$ was applied as a foliar spray to calibrachoa, dianthus, verbena, and dahlia on 27 Feb. 2013. At Mast, paclobutrazol at 1 ppm was applied as a substrate drench with a volume delivering $4 \mathrm{fl} \mathrm{oz}$ per pot to all plants on 22 Feb. 2013. No plant growth retardants were used at KruegerMaddux, Kube Pak, and MSU.

Lighting Treatments. At each site, 4-h NI lighting treatments were delivered by the $\mathrm{R}+\mathrm{W}+\mathrm{FR}$ LED lamps (GreenPower LED flowering DR/W/FR 120 V, E26; Philips, Eindhoven, The Netherlands) and one or two conventional lamp types at the discretion of the grower (Table 1). All lamps operated from 2200 to 0200 HR every night to provide NI lighting, as controlled by an environmental control computer or a timer. At all sites except MSU, plants received the natural photoperiod. At MSU, opaque black cloth enclosing greenhouse benches was closed at $1700 \mathrm{HR}$ and opened at $0800 \mathrm{HR}$ to provide a truncated $9-\mathrm{h}$ SD for all treatments. In addition to the LED and conventional lamp treatments, CfAHR, MSU, and Kube Pak provided control treatments, including an unlighted natural SD treatment at CfAHR, a truncated 9-h SD treatment at MSU, or a CFL treatment at Kube Pak. At all sites, if any two treatments were in close proximity, a light barrier, such as a blackout fabric or black plastic sheet, was manually positioned between the treatments at night to block all direct light from adjacent treatment(s). To avoid shade 
Table 1. Trial period, lighting treatments, average daily temperature (ADT), and daily light integral (DLI) at different trial sites, including C. Raker \& Sons (Litchfield, MI), the Center for Applied Horticultural Research at Altman Plants [Vista, CA (CfAHR)], Henry Mast Greenhouse (Byron Center, MI), Krueger-Maddux Greenhouses (Sunman, IN), Kube Pak (Allentown, NJ), and two separate greenhouses at Michigan State University [East Lansing (MSU)], in a coordinated trial. Plants were grown under short days with or without 4-h night-interruption lighting from high-pressure sodium (HPS), incandescent (INC), compact fluorescent (CFL), or red + white + far-red light-emitting diode (LED) lamps. The short-day (SD) treatment at CfAHR was a natural day, whereas that at MSU was truncated to $9 \mathrm{~h}$.

\begin{tabular}{|c|c|c|c|c|c|c|c|}
\hline Trial site & $\begin{array}{l}\text { Trial period } \\
(2013)\end{array}$ & $\begin{array}{l}\text { Lamp } \\
\text { type }\end{array}$ & $\begin{array}{c}\text { Lamp } \\
\text { power }(W)\end{array}$ & $\begin{array}{c}\text { Lamps } \\
\text { (no./treatment) }\end{array}$ & $\begin{array}{l}\text { Photoperiod } \\
(\mathrm{h})^{\mathrm{z}}\end{array}$ & $\begin{array}{c}\operatorname{ADT} \\
{\left[\text { mean } \pm \mathrm{SD}\left({ }^{\circ} \mathrm{F}\right)\right]^{\mathrm{y}}}\end{array}$ & $\begin{array}{c}\mathrm{DLI} \\
\left(\mathrm{mol} \cdot \mathrm{m}^{-2} \cdot \mathrm{d}^{-1}\right)\end{array}$ \\
\hline \multirow[t]{2}{*}{ C. Raker \& Sons } & 1 Feb.-10 Apr. & HPS & 400 & 2 & $10.02-13.12$ & $68.0 \pm 1.4$ & 17.4 \\
\hline & & LED & 14 & 8 & & $64.1 \pm 1.0$ & 12.1 \\
\hline \multirow[t]{3}{*}{ CfAHR } & 2 Feb.-4 Apr. & SD & $-^{x}$ & - & $10.62-12.63$ & $70.6 \pm 8.3$ & 20.5 \\
\hline & & INC & 150 & 2 & & $71.1 \pm 6.6$ & 20.8 \\
\hline & & LED & 14 & 2 & & $70.8 \pm 10.0$ & 19.4 \\
\hline \multirow{2}{*}{$\begin{array}{l}\text { Krueger-Maddux } \\
\text { Greenhouses }\end{array}$} & 28 Jan.-20 Apr. & INC & 100 & 5 & $10.08-13.42$ & $62.0^{\mathrm{w}}$ & 13.3 \\
\hline & & LED & 14 & 6 & & & \\
\hline \multirow[t]{3}{*}{ Kube Pak } & 18 Feb.-4 Apr. & CFL & 15 & 3 & $10.82-12.78$ & $65.7 \pm 3.1$ & 9.0 \\
\hline & & INC & 150 & 3 & & & \\
\hline & & LED & 14 & 6 & & & \\
\hline MSU house 10E & 5 Feb.-24 June & SD & - & 一 & 9.00 & $70.1 \pm 3.3$ & - \\
\hline & & INC & 60 & 2 & & $69.3 \pm 3.3$ & 11.3 \\
\hline & & LED & 14 & 2 & & $69.1 \pm 2.7$ & 11.3 \\
\hline
\end{tabular}

${ }^{2}$ The photoperiod was from sunrise to sunset at each trial site except at MSU, which was truncated with black cloth.

${ }^{y}\left({ }^{\circ} \mathrm{F}-32\right) \div 1.8={ }^{\circ} \mathrm{C}$.

${ }^{\mathrm{N}}$ No data.

wTemperature setpoint; actual temperature was not recorded.

cast by the black screens during the day, they were pulled closed between 1600 and $2000 \mathrm{HR}$ and retracted before 0900 HR. At Raker and Kube Pak, the treatments were far enough apart to avoid light contamination. At Raker, CfAHR, Mast, KruegerMaddux, Kube Pak, and MSU, the LED lamps were installed $3.5,3.0$, $7.0,5.5,7.0$, and $3.1 \mathrm{ft}$, respectively, above plants and 3 to $10 \mathrm{ft}$ apart. The conventional lamps were installed as per each grower's lighting standards. At Raker, two HPS lamps (400 W, PL2000; P.L. Light Systems Beamsville, ON, Canada) were hung $3.5 \mathrm{ft}$ above the bench surface and 12 $\mathrm{ft}$ apart. At CfAHR, four INC lamps were placed $3 \mathrm{ft}$ above benches and 3 $\mathrm{ft}$ apart. At Mast, one HPS lamp (400 W, PL2000; P.L. Light Systems) was hung $7 \mathrm{ft}$ above plants. At KruegerMaddux, five INC lamps with metallic pie plates acting as reflectors were hung $4 \mathrm{ft}$ above plants and $5 \mathrm{ft}$ apart. At Kube Pak, three INC or CFL lamps were hung $10 \mathrm{ft}$ above plants and $10 \mathrm{ft}$ apart.

At MSU, two INC lamps were hung $2.5 \mathrm{ft}$ above plants and $2.5 \mathrm{ft}$ apart and, along with the LEDs, were covered with multiple layers of aluminum mesh to achieve an average photon flux of $2 \mu \mathrm{mol} \cdot \mathrm{m}^{-2} \cdot \mathrm{s}^{-1}$ between 400 and $800 \mathrm{~nm}$ (and was always between $\mathrm{l}$ and $\left.3 \mu \mathrm{mol} \cdot \mathrm{m}^{-2} \cdot \mathrm{s}^{-1}\right)$. The spectral distribution of the LED and INC lamps was measured by a spectroradiometer (PS-200; StellarNet, Tampa, FL), and the phytochrome photoequilibrium was estimated according to Sager et al. 1988 (Fig. 1). Supplemental lighting provided by HPS lamps was used for all plants from 0800 to $1700 \mathrm{HR}$, delivering a photosynthetic photon flux $(P P F)$ of 60 to $90 \mu \mathrm{mol} \cdot \mathrm{m}^{-2} \cdot \mathrm{s}^{-1}$ at plant canopy. Controlled by an environmental control computer, the HPS lamps were automatically switched on when the ambient PPF was lower than $185 \mu \mathrm{mol} \cdot \mathrm{m}^{-2} \cdot \mathrm{s}^{-1}$ and off when the ambient $P P F$ was greater than $370 \mu \mathrm{mol} \cdot \mathrm{m}^{-2} \cdot \mathrm{s}^{-1}$.

DATA COlleCtion AND ANALYSIS. At all sites, date of first open flower was recorded for 12 plants in each treatment that were randomly selected at the beginning of the trial. Additional data were recorded at MSU, such as date of first visible flower bud or inflorescence (VB), number of $\mathrm{VB}$, and main stem length at flowering. For EWBS and WPC petunia, the stem with the first open flower was measured for stem length. All plants were checked every 1 to 2 $\mathrm{d}$ for first flowering except at Kube Pak, where flowering was checked once or twice a week. Days to flower from the start of lighting treatments (and at Kube Pak from when plants were transplanted) and flowering percentage were subsequently calculated for each cultivar in each treatment. The trials ended on 10 Apr. 2013, 4 Apr. 2013, 8 Apr. 2013, 20 Apr. 2013, 4 Apr. 2013, and 24 June 2013 at Raker, CfAHR, Mast, Krueger-Maddux, Kube Pak, and MSU, respectively. The photoperiod from sunrise to sunset, actual average daily temperature (ADT), and photosynthetic daily light integral (DLI) for each site are provided in Table 1 . At Raker, CfAHR, and Mast, a weather station (WatchDog 2400; Spectrum Technologies, Aurora, IL) measured temperature and photosynthetically active radiation $(P A R)$. At KruegerMaddux, a light meter (Lightscout DLI 100, Spectrum Technologies) estimated the DLI, and the grower 


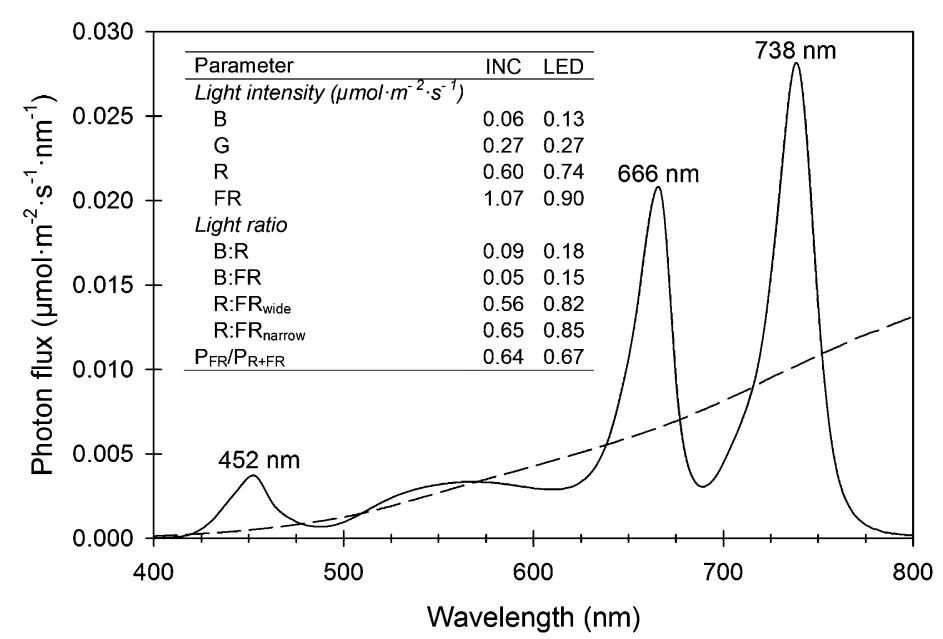

Fig. 1. Spectral distribution, intensity of blue $[B(400-500 \mathrm{~nm})]$, green $[\mathrm{G}(500$ $600 \mathrm{~nm})]$, red $[\mathrm{R}(600-700 \mathrm{~nm})]$, and far-red $[\mathrm{FR}(700-800 \mathrm{~nm})]$ light, light ratio, and estimated phytochrome photoequilibria $\left[\mathrm{P}_{\mathrm{FR}} / \mathbf{P}_{\mathrm{R}+\mathrm{FR}}\right.$ (the proportion of FRabsorbing phytochromes in the pool of $\mathrm{R}$ - and FR-absorbing phytochromes; Sager et al., 1988)] of incandescent [INC (dashed line)] and R + white + FR lightemitting diode [LED (solid line)] lamps used in a coordinated trial. R:FR wide was calculated as 600 to $700 \mathrm{~nm}: 700$ to $800 \mathrm{~nm}$; R:FR narrow was calculated as 655 to $665 \mathrm{~nm}: 725$ to $735 \mathrm{~nm}$.

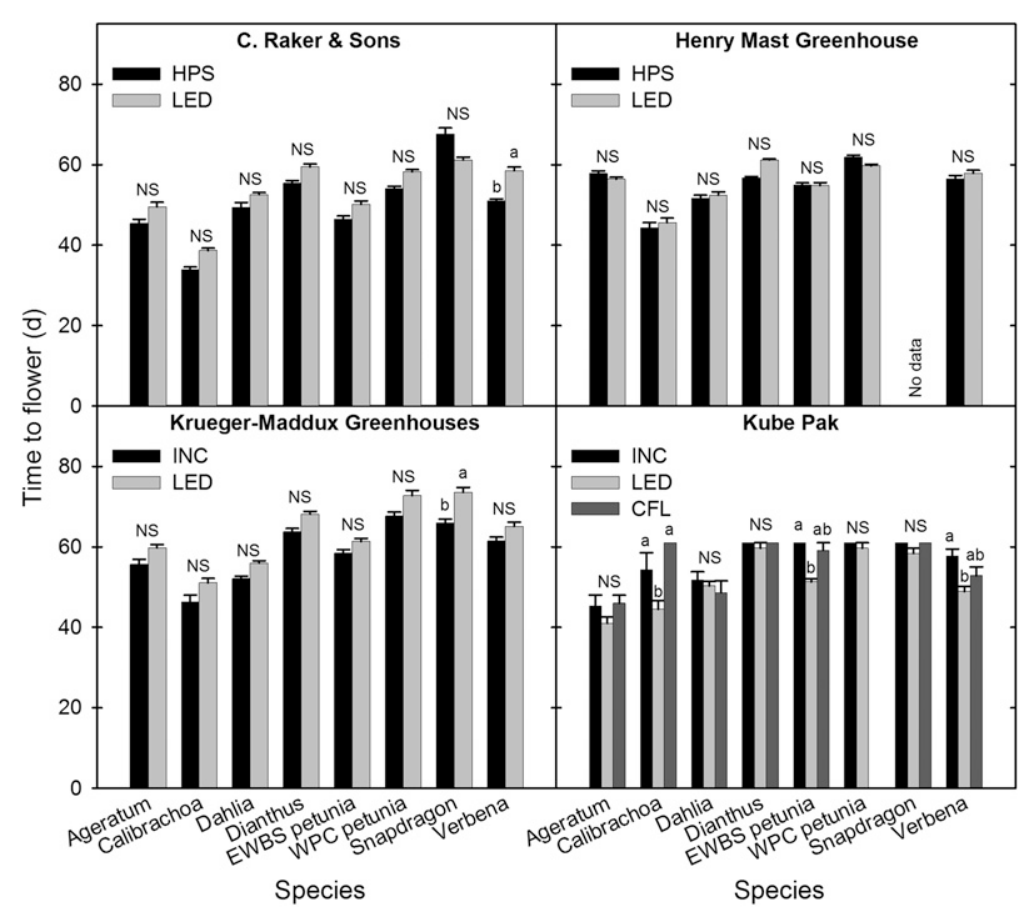

Fig. 2. Days to flower for eight bedding plant crops grown at four commercial greenhouses, including C. Raker \& Sons (Litchfield, MI), Henry Mast Greenhouse (Byron Center, MI), Krueger-Maddux Greenhouses (Sunman, IN), and Kube Pak (Allentown, NJ), in a coordinated trial. Plants were grown under short days with 4-h night-interruption lighting from high-pressure sodium (HPS), incandescent (INC), compact fluorescent (CFL), or red + white + far-red light-emitting diode (LED) lamps. Values followed by different letters within species are significantly different by Tukey's honest significant difference test at $P \leq 0.05$ (NS = nonsignificant). Error bars indicate SE; EWBS = 'Easy Wave Burgundy Star', WPC = 'Wave Purple Classic'.

read instantaneous temperatures with a thermostat and thermometers but did not record actual data. At Kube
Pak, a weather tracker (WatchDog 305, Spectrum Technologies) measured temperature and $P A R$. At MSU, line quantum sensors (Apogee Instruments, Logan, UT) positioned horizontally at plant height measured $P A R$ every $10 \mathrm{~s}$, and a data logger (CRl0; Campbell Scientific, Logan, UT) recorded hourly averages. An aspirated thermocouple [36-gauge (0.005-inch diameter) type E] on each bench measured air temperature every $10 \mathrm{~s}$, and the same data logger recorded hourly averages. Data were analyzed with the SAS (version 9.3; SAS Institute, Cary, NC) mixedmodel (PROC MIXED) and glimmixmodel (PROC GLIMMIX) procedures, and pairwise comparisons between treatments were performed with Tukey's honest significant difference test $(P=$ $0.05)$. At MSU, data from two greenhouses were pooled if the interaction between treatment and house was not significant or responses showed similar trends.

\section{Results}

RAKER. All plants flowered under NI lighting treatments delivered by either the HPS lamps or LEDs (data not shown). There was no significant effect of lamp type on flowering time for any crop except verbena, which flowered $\approx 8 \mathrm{~d}$ earlier under the HPS lamps (Fig. 2). Although no data were recorded, the grower noted (P. Karlovich, personal communication) that plants under the HPS lamps were of higher visual quality than those under the LEDs: all cultivars appeared darker green and shorter under the HPS lamps.

CFAHR. All plants under the INC lamps and LEDs flowered at about the same time, whereas some of the LDPs did not flower under the natural SDs (Fig. 3 or data not shown). Only $8 \%$ of WPC petunia flowered under SDs before the trial ended. For ageratum, dahlia, dianthus, EWBS petunia, and verbena, there were no significant differences in flowering time among treatments (Fig. 4). In contrast, calibrachoa and snapdragon flowered 28 and $8 \mathrm{~d}$ earlier, respectively, under the NI lighting treatments than under SDs. The grower observed (L. Villavicencio, personal communication) that calibrachoa and snapdragon under the NI lighting treatments appeared more elongated than plants under SDs, and plants under the LEDs were more compact than those under the INC lamps. Verbena under the 


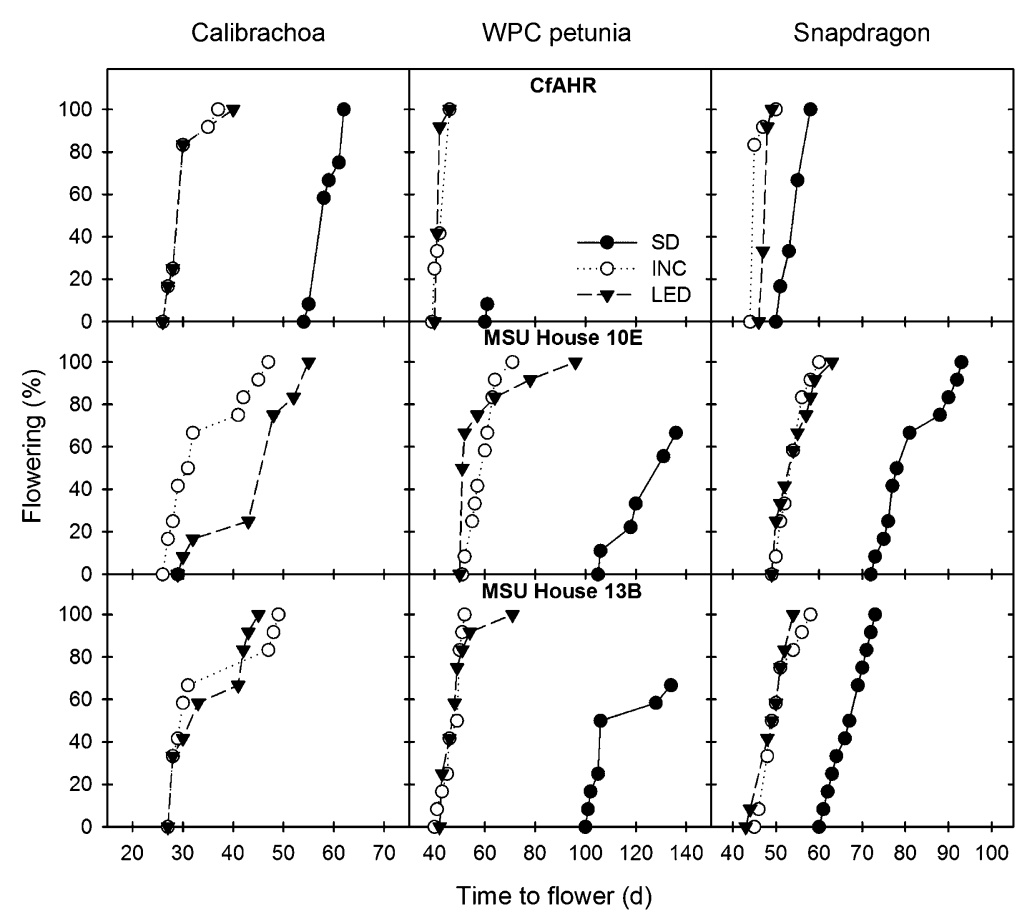

Fig. 3. Flowering percentage of 'Callie Deep Yellow' calibrachoa, 'Wave Purple Classic' (WPC) petunia, and 'Liberty Classic Yellow' snapdragon at the Center for Applied Horticultural Research at Altman Plants [Vista, CA (CfAHR)] and two separate greenhouses (houses $10 \mathrm{E}$ and 13B) at Michigan State University [East Lansing (MSU)] in a coordinated trial. Plants were grown under a short-day (SD) treatment with or without 4-h night-interruption lighting from incandescent (INC) or red + white + far-red light-emitting diode (LED) lamps. The SD treatment at CfAHR had a natural photoperiod, whereas the photoperiod at MSU was truncated to $9 \mathrm{~h}$.

LEDs appeared taller than plants under the INC lamps, but no data were recorded.

Mast. All plants flowered similarly under the NI lighting treatments delivered by HPS lamps or LEDs (Fig. 2), except only $8 \%$ of snapdragon under the HPS lamps had flowered before the trial ended. Although complete data of snapdragon under the HPS lamps were not collected, the grower estimated (B. De Vries, personal communication) that flowering was delayed by $\approx 5 \mathrm{~d}$ under the HPS lamps compared with the LEDs.

KrUeger-MAdDUX. All plants flowered similarly under the NI lighting treatments delivered by INC lamps or LEDs except snapdragon, which flowered $\approx 8 \mathrm{~d}$ earlier under the INC lamps (Fig. 2). According to the grower (D. Gibbs, personal communication), plants under the INC lamps appeared more elongated than those under the LEDs.

Kube PAK. WPC petunia did not flower under the NI lighting treatment delivered by CFL lamps before the trial ended. For ageratum, dahlia, dianthus, and snapdragon, flowering time was similar among the three NI lighting treatments (Fig. 2). EWBS petunia and verbena flowered 10 and $9 \mathrm{~d}$ earlier, respectively, under the LEDs than under the INC lamps, and calibrachoa flowered 10 to $17 \mathrm{~d}$ earlier under the LEDs than under the INC or CFL lamps. Flowering percentage under the CFL or INC lamps was lower than that under the LEDs for calibrachoa, dahlia, dianthus, EWBS and WPC petunia, and snapdragon (data not shown). For example, flowering percentage of WPC petunia under the CFL lamps, INC lamps, and LEDs was $0 \%, 17 \%$, and $50 \%$, respectively, at the end of the trial.

MSU. All plants flowered under either the INC lamps or LEDs. Calibrachoa did not flower under SDs before the trial ended (Fig. 3). Twothirds of WPC petunia under SDs flowered in houses $10 \mathrm{E}$ and $13 \mathrm{~B}$. Ageratum, dianthus, EWBS and
WPC petunia, and snapdragon flowered similarly under NI lighting treatments delivered by INC lamps or LEDs, and earlier than under SDs (Fig. 4). The flowering responses of calibrachoa and dahlia were inconsistent in houses $10 \mathrm{E}$ and $13 \mathrm{~B}$. Verbena flowered earlier under the INC lamps and LEDs than under SDs, but flowering was most rapid under the INC lamps in house $10 \mathrm{E}$. The trends for days to VB were similar to those of days to flower (Table 2). Except for dahlia and WPC petunia, plant height at flowering was similar under the INC lamps and LEDs. The stem with the first flower of WPC petunia was $\approx 5 \mathrm{~cm}$ longer under the LEDs than under the INC lamps. Except for dianthus and EWBS petunia in house $10 \mathrm{E}, \mathrm{VB}$ number at flowering was similar under the INC lamps and LEDs.

\section{Discussion}

In most cases, flowering time of the bedding plants tested was similar under NI lighting provided by INC or HPS lamps and the $\mathrm{R}+\mathrm{W}+\mathrm{FR}$ LEDs. The exceptions included verbena at Raker (delayed under the LEDs compared with HPS lamps); snapdragon at Krueger-Maddux (delayed under the LEDs compared with INC lamps); calibrachoa, EWBS petunia, and verbena at Kube Pak (delayed under INC lamps compared with the LEDs); and calibrachoa and verbena in house $10 \mathrm{E}$ at MSU (delayed under the LEDs compared with INC lamps). At MSU, stem length and VB number at flowering were generally similar under the NI lighting treatments. Therefore, we conclude that in most instances, the $\mathrm{R}+\mathrm{W}+\mathrm{FR}$ LEDs are as effective as lamps traditionally used in greenhouses, such as INC and HPS, when delivered as 4-h NI lighting.

Night-interruption lighting promotes flowering of LDPs when the natural days are short (Devlin, 2008). Generally, 4 h of NI lighting is effective for most LDPs. For example, more than $80 \%$ of the LDPs that received 4-h NI lighting treatments from INC or HPS lamps formed VB within 16 weeks, whereas most LDPs remained vegetative under a 9-h SD (Blanchard and Runkle, 2010). In the trials performed at MSU, the NI lighting treatments promoted 


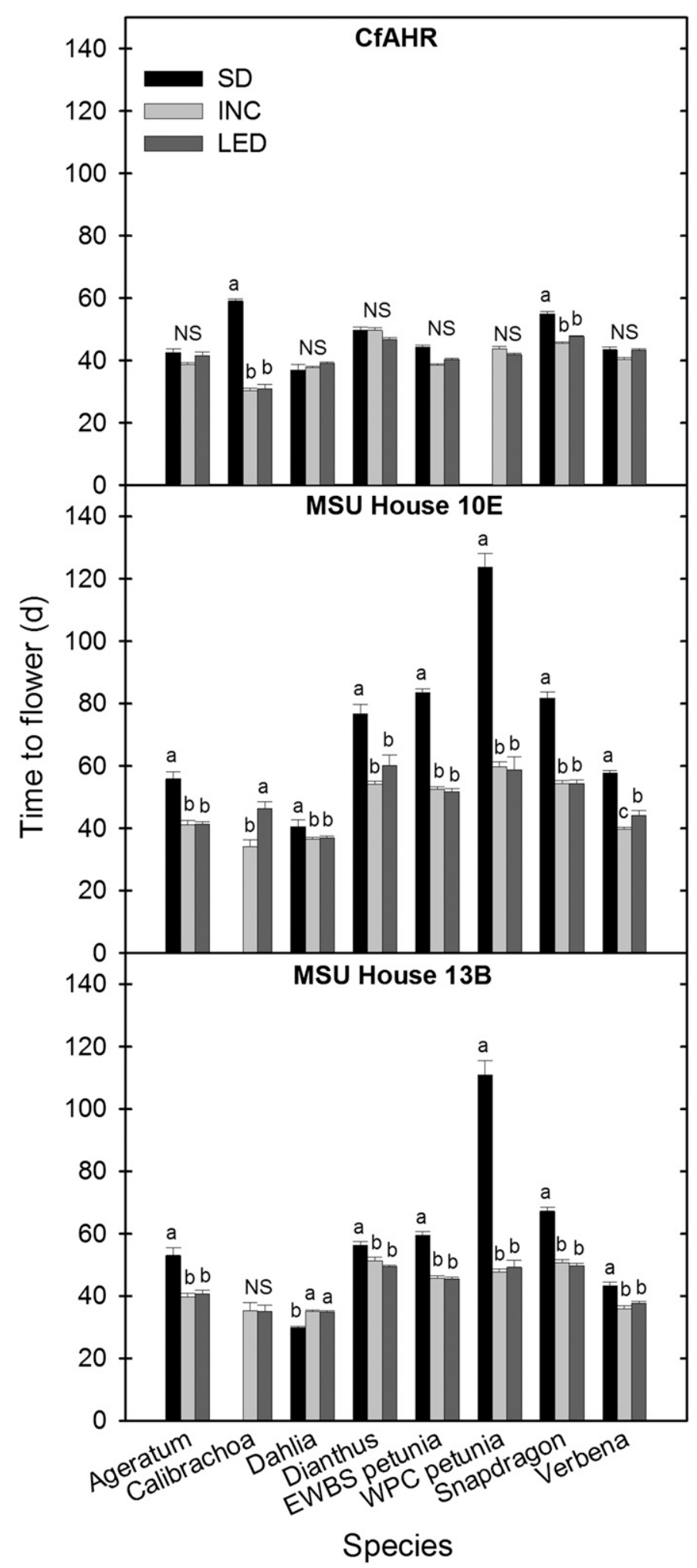

Fig. 4. Days to flower of eight bedding plant crops grown at the Center for Applied Horticultural Research at Altman Plants [Vista, CA (CfAHR)] and two separate greenhouses (houses 10E and 13B) at Michigan State University [East Lansing (MSU)] in a coordinated trial. Plants were grown under a short-day (SD) treatment with or without a 4-h night interruption from incandescent (INC) or red + white + far-red light-emitting diode (LED) lamps. The SD treatment at CFAHR had a natural photoperiod, whereas the photoperiod at MSU was truncated to $9 \mathrm{~h}$. Values followed by different letters within species are significantly different by Tukey's honest significant difference test at $P \leq 0.05$ (NS = nonsignificant); EWBS = 'Easy Wave Burgundy Star', WPC = 'Wave Purple Classic'. flowering of most LDPs compared with the 9-h SD treatment. The promoting effects of NI lighting treatments at CfAHR were somewhat less compared with that of the natural SD treatment. The natural daylength from sunrise to sunset at CfAHR increased from 10 h 37 min on 2 Feb. 2013 to 12 h 38 min on 4 Apr. 2013. Therefore, compared with the $9-\mathrm{h}$ SD at MSU, plants at CfAHR were exposed to a longer natural photoperiod, which could have been sufficient to promote flowering of some crops. However, NI lighting accelerated flowering of calibrachoa, WPC petunia, and snapdragon at CfAHR compared with the SD treatment, indicating these crops have a longer photoperiod for flowering than the other crops. The same strong photoperiodic responses of these crops occurred at MSU.

Phytochrome is primarily an $\mathrm{R}$ and FR light-absorbing photoreceptor that regulates flowering of LDPs. The radiation distribution determines the amounts of induced R-absorbing $\left(\mathrm{P}_{\mathrm{R}}\right)$ and FR-absorbing $\left(\mathrm{P}_{\mathrm{FR}}\right)$ forms of phytochrome in photoperiodic plants, resulting in a steady-state phytochrome photoequilibrium (defined as $\left.\mathrm{P}_{\mathrm{FR}} / \mathrm{P}_{\mathrm{R}+\mathrm{FR}}\right)$ (Sager et al., 1988). Night-interruption lighting provided by $\mathrm{R}$ and FR FL lamps with an R:FR of 0.5 or 1.0 was most effective at promoting flowering of the LDP lisianthus [Eustoma grandiflorum (Yamada et al., 2009)]. Similarly, day-extension lighting provided by a mixture of $\mathrm{R}$ and FR LEDs with an R:FR between 0.23 and 0.71 promoted flowering of the LDP baby's breath [Gypsophila paniculata (Nishidate et al., 2012)]. Another study demonstrated that NI lighting provided by experimental LED fixtures with an estimated $\mathrm{P}_{\mathrm{FR}} / \mathrm{P}_{\mathrm{R}+\mathrm{FR}}$ of 0.63 $(\mathrm{R}: \mathrm{FR}=0.66)$ or $0.72(\mathrm{R}: \mathrm{FR}=1.07)$ most effectively promoted flowering of LDPs (Craig and Runkle, 2012). The flowering responses under these LEDs were also similar to those under the INC lamps with a $\mathrm{P}_{\mathrm{FR}} / \mathrm{P}_{\mathrm{R}+\mathrm{FR}}$ of 0.64 $(\mathrm{R}: \mathrm{FR}=0.59)$, indicating LEDs that emit an intermediate $\mathrm{P}_{\mathrm{FR}} / \mathrm{P}_{\mathrm{R}+\mathrm{FR}}$ are a feasible replacement for INC lamps. In this study, the $\mathrm{P}_{\mathrm{FR}} / \mathrm{P}_{\mathrm{R}+\mathrm{FR}}$ of the INC lamps and $\mathrm{R}+\mathrm{W}+\mathrm{FR}$ LEDs was $0.64(\mathrm{R}: \mathrm{FR}=0.56)$ and 0.67 (R:FR $=0.82$ ), respectively. Therefore, the similar proportions of the active form of phytochrome, 
Research Reports

Table 2. Flowering characteristics of eight bedding plant crops grown in two separate greenhouses (houses 10E and 13B) at Michigan State University (East Lansing). Plants were grown under a 9-h short day (SD) or an SD with 4-h nightinterruption (NI) lighting from incandescent (INC) or red + white + far-red light-emitting diode (LED) lamps.

\begin{tabular}{|c|c|c|c|c|c|c|c|c|}
\hline \multirow[b]{2}{*}{ Photoperiod treatment } & \multicolumn{2}{|c|}{ Time to visible bud (d) } & \multicolumn{2}{|c|}{ Time to flower (d) } & \multicolumn{2}{|c|}{ Stem length $(\mathrm{cm})^{\mathrm{z}}$} & \multicolumn{2}{|c|}{ Visible flower bud (no.) } \\
\hline & $10 \mathrm{E}$ & 13B & $10 \mathrm{E}$ & 13B & $10 \mathrm{E}$ & 13B & $10 \mathrm{E}$ & 13B \\
\hline \multicolumn{9}{|c|}{ Ageratum } \\
\hline SD & \multicolumn{2}{|c|}{$27 a^{y, x}$} & \multicolumn{2}{|c|}{$52 \mathrm{a}^{\mathrm{y}}$} & $9.7 \mathrm{~b}$ & $11.2 \mathrm{a}$ & \multicolumn{2}{|c|}{$13.8 \mathrm{a}^{\mathrm{y}}$} \\
\hline INC NI & \multicolumn{2}{|c|}{$22 \mathrm{~b}$} & \multicolumn{2}{|c|}{$40 \mathrm{~b}$} & $12.4 \mathrm{a}$ & $9.9 \mathrm{a}$ & \multicolumn{2}{|c|}{$14.8 \mathrm{a}$} \\
\hline LED NI & \multicolumn{2}{|c|}{$21 \mathrm{~b}$} & \multicolumn{2}{|c|}{$41 \mathrm{~b}$} & $12.0 \mathrm{a}$ & $11.1 \mathrm{a}$ & \multicolumn{2}{|c|}{$15.0 \mathrm{a}$} \\
\hline Treatment & \multicolumn{2}{|c|}{$* * * \mathrm{w}$} & \multicolumn{2}{|c|}{$* * *$} & *v & NS & \multicolumn{2}{|c|}{ NS } \\
\hline House & \multicolumn{2}{|c|}{$\mathrm{NS}^{\mathrm{u}}$} & & & & & & \\
\hline Treatment $\times$ house & & & & & & & & \\
\hline & & & Cali & & & & & \\
\hline SD & $一^{\mathrm{t}}$ & - & - & - & & & & \\
\hline INC NI & $27 \mathrm{~b}$ & $28 \mathrm{a}$ & $34 \mathrm{~b}$ & $35 \mathrm{a}$ & & & & \\
\hline LED NI & $37 \mathrm{a}$ & $28 \mathrm{a}$ & $46 \mathrm{a}$ & $35 \mathrm{a}$ & & & & \\
\hline Treatment & * & NS & * & NS & & & & \\
\hline House & & & & & & & & \\
\hline Treatment $\times$ house & & & & & & & & \\
\hline & & & & & & & & \\
\hline SD & $23 \mathrm{a}$ & $17 \mathrm{~b}$ & $41 \mathrm{a}$ & $30 \mathrm{~b}$ & & & & \\
\hline INC NI & $22 \mathrm{a}$ & $21 \mathrm{a}$ & $37 \mathrm{~b}$ & $35 \mathrm{a}$ & & & & \\
\hline LED NI & $23 a$ & $22 \mathrm{a}$ & $37 \mathrm{~b}$ & $35 \mathrm{a}$ & & & & \\
\hline Treatment & NS & $* * *$ & * & $* * *$ & & & & \\
\hline House & & & & & & & & \\
\hline Treatment $\times$ house & & & & & & & & \\
\hline & & & Dio & & & & & \\
\hline SD & & & & & & & $1.1 \mathrm{c}$ & $5.0 \mathrm{a}$ \\
\hline INC NI & & & & & & & $6.1 \mathrm{a}$ & $6.6 \mathrm{a}$ \\
\hline LED NI & & & & & & & $3.8 \mathrm{~b}$ & $6.6 \mathrm{a}$ \\
\hline Treatment & & & & & & & $* * *$ & NS \\
\hline House & & & & & & & & \\
\hline Treatment $\times$ house & & & & & & & & \\
\hline & & 'Easy & ave Burg & Star' 1 & nia & & & \\
\hline SD & & & & & $22.0 \mathrm{a}$ & $18.4 \mathrm{a}$ & $14.1 \mathrm{~b}$ & $10.9 \mathrm{~b}$ \\
\hline INC NI & & & & & $14.4 \mathrm{~b}$ & $16.9 \mathrm{ab}$ & 19.8 a & $16.3 \mathrm{a}$ \\
\hline LED NI & & & & & $13.2 \mathrm{~b}$ & $15.4 \mathrm{~b}$ & $14.3 \mathrm{~b}$ & $16.0 \mathrm{a}$ \\
\hline Treatment & & & & & $* * *$ & * & * & * \\
\hline House & & & & & & & & \\
\hline Treatment $\times$ house & & & & & & & & \\
\hline & & & e Purple & sic'petu & & & & \\
\hline SD & & & & & & & & \\
\hline INC NI & & & & & & & & \\
\hline LED NI & & & & & & & & \\
\hline Treatment & & & & & & & & \\
\hline House & & & & & & & & \\
\hline Treatment $\times$ house & & & & & & & & \\
\hline & & & Snap & & & & & \\
\hline SD & & & & & & & & \\
\hline INC NI & & & & & & & & \\
\hline LED NI & & & & & & & & \\
\hline Treatment & & & & & & & & \\
\hline House & & & & & & & & \\
\hline Treatment $\times$ house & & & & & & & & \\
\hline
\end{tabular}

(Continued on next page) 
Table 2. (Continued) Flowering characteristics of eight bedding plant crops grown in two separate greenhouses (houses $10 \mathrm{E}$ and 13B) at Michigan State University (East Lansing). Plants were grown under a 9-h short day (SD) or an SD with 4-h night-interruption (NI) lighting from incandescent (INC) or red + white + far-red light-emitting diode (LED) lamps.

\begin{tabular}{|c|c|c|c|c|c|c|}
\hline \multirow[b]{2}{*}{ Photoperiod treatment } & \multicolumn{2}{|c|}{ Time to visible bud (d) } & \multicolumn{2}{|c|}{ Time to flower (d) } & Stem length $(\mathrm{cm})^{\mathrm{z}}$ & Visible flower bud (no.) \\
\hline & $10 \mathrm{E}$ & 13B & $10 \mathrm{E}$ & 13B & $10 \mathrm{E}$ & 13B \\
\hline \multicolumn{7}{|c|}{ Verbena } \\
\hline INC NI & $22 \mathrm{~b}$ & $21 \mathrm{~b}$ & $40 \mathrm{c}$ & $36 \mathrm{~b}$ & $15.3 \mathrm{a}$ & $6.1 \mathrm{~b}$ \\
\hline LED NI & $26 \mathrm{a}$ & $21 \mathrm{~b}$ & $44 \mathrm{~b}$ & $38 \mathrm{~b}$ & $15.0 \mathrm{a}$ & $6.3 \mathrm{~b}$ \\
\hline Treatment & $* * *$ & $* * *$ & $* * *$ & *** & *** & $* * *$ \\
\hline
\end{tabular}

${ }^{\mathrm{z}} 1 \mathrm{~cm}=0.3937$ inch.

yata pooled for analysis.

'Means within species and columns followed by different letters are significantly different by Tukey's honest significant difference test at $P \leq 0.05$.

"Significant at $P \leq 0.001$.

vignificant at $P \leq 0.05$.

"Nonsignificant.

${ }^{\mathrm{t} N o}$ data.

$\mathrm{P}_{\mathrm{FR}}$, could account for similar flowering responses under these two NI lighting treatments.

Standard HPS lamps with a considerably higher R:FR $\left(>4.0 ; \mathrm{P}_{\mathrm{FR}} /\right.$ $\mathrm{P}_{\mathrm{R}+\mathrm{FR}}>0.8$ ) could be less effective at promoting flowering of some LDPs than lamps with a lower R:FR (Blanchard and Runkle, 2009, 2010; Runkle and Heins, 2001). For example, coreopsis (Coreopsis grandiflora) and rudbeckia (Rudbeckia hirta) flowered 8 to $31 \mathrm{~d}$ earlier under 4 -h NI lighting provided by INC lamps than rotating HPS lamps (Blanchard and Runkle, 2010). At Mast, only 8\% of snapdragon plants under the HPS lamps had flowered before the trial ended, whereas all plants had flowered under the LEDs. However, at Raker, verbena under the HPS lamps flowered earlier than plants under the LEDs. The earlier flowering of verbena could be attributed to a higher ADT (by $3.9^{\circ} \mathrm{F}$ ) under the HPS lamps (Table 1). Similarly, the earlier flowering at CfAHR compared with that at the other sites could at least partially be explained by the higher ADT at CfAHR. A previous study showed that flowering time of 15 ornamental annual crops was shortened as the ADT increased (Vaid and Runkle, 2013). With the linear equation correlating the ADT and the flowering rate of petunia in this study, differences in flowering time of EWBS petunia and snapdragon among our trial sites can be explained. Specifically, the models predict that EWBS petunia and snapdragon under the LEDs would flower 7 and $9 \mathrm{~d}$ earlier, respectively, at CfAHR than at Raker, and the actual flowering time was accelerated by 10 and $13 \mathrm{~d}$, respectively. The slight discrepancies between the estimated and actual flowering time could be from different genetics of cultivars, seedling maturity at transplant time, photoperiod, and DLI.

An increase in the DLI can also accelerate flowering (Currey and Erwin, 2011; Oh et al., 2009). For example, days to flower decreased for 'Apple Blossom' petunia, salvia (Salvia coccinea), and 'Dreamland Rose' zinnia as the DLI increased 12 to 19 $\mathrm{mol} \cdot \mathrm{m}^{-2} \cdot \mathrm{d}^{-1}$ (Faust et al., 2005). Similarly, flowering time of 'Pocket Rose' snapdragon grown at $20^{\circ} \mathrm{C}$ was shortened by $13 \mathrm{~d}$ when the DLI increased from 10.5 to $17.5 \mathrm{~mol} \cdot \mathrm{m}^{-2} \cdot \mathrm{d}^{-1}$ (Warner and Erwin, 2005). Therefore, at Raker, a higher DLI (by $5.3 \mathrm{~mol} \cdot \mathrm{m}^{-2} \cdot \mathrm{d}^{-1}$ ) could also account for the earlier flowering of verbena under the HPS lamps than under the LEDs. Average days to flower for all crops under the LEDs at Raker, Mast, and Krueger-Maddux was $29 \%, 36 \%$, and $53 \%$ longer, respectively, than at CfAHR. The DLI in California is typically higher than that in the other trial sites (Korczynski et al., 2002) and, in our trial, was greater than at the other sites. Therefore, the earlier flowering at CfAHR could at least partly be attributed to a higher DLI. The ADT and DLI can also interact to influence flowering time of various ornamental crops. According to a nonlinear ADT and DLI model developed to predict flowering time of 'Dreams Neon Rose' petunia grown under long days (Blanchard et al., 2011), this crop would flower $6 \mathrm{~d}$ earlier under the LEDs with the actual ADT and DLI at CfAHR than at Raker. In our trial, EWBS and WPC petunia flowered 10 and $16 \mathrm{~d}$ earlier, respectively, under the LEDs at CfAHR than at Raker, confirming that a high ADT and DLI can together accelerate flowering.

Delayed flowering under the CFL lamps at Kube Pak is in agreement with a previous report (Runkle et al., 2012) that WPC petunia flowered 2 to 3 weeks later under 4 -h NI lighting provided by CFL lamps than INC lamps, which indicates that a complete replacement of INC lamps with CFL lamps can delay flowering of some LDPs. The R:FR of CFL lamps, which emit little FR light, is higher than that of INC lamps (B. Bugbee, unpublished data; Padhye and Runkle, 2009; Runkle et al., 2012). Night-interruption lighting with a high R:FR was less effective at promoting flowering of LDPs such as petunia, snapdragon, lisianthus, and viola (Viola $\times$ wittrockiana) compared with a moderate R:FR (Craig and Runkle, 2012; Kim et al., 2002; Runkle and Heins, 2001; Sato et al., 2009; Yamada et al., 2009). Therefore, CFL lamps or LEDs with little or no FR light are generally not as effective at controlling flowering of some LDPs.

Given the comparable effectiveness of the $\mathrm{R}+\mathrm{W}+\mathrm{FR}$ LEDs and conventional light sources, factors such as energy availability and cost, lighting use per year, lamp cost and longevity, and availability of energy rebates from utility companies are among the factors that should be considered when choosing a light source for photoperiodic lighting. 
The R + W + FR LEDs consume only $14 \mathrm{~W}$ per lamp, making them more efficient than most conventional lamp types. The useful lifetime of these LEDs at $77{ }^{\circ} \mathrm{F}$ and $90 \%$ intensity is at least 20,000 h (Philips, 2014), whereas that of INC bulbs is usually $\approx 1000 \mathrm{~h}$ (Lim et al., 2012). The greater energy efficiency and much longer lifetime should be weighed against the higher purchase price of the LEDs. For example, to provide similar photoperiodic lighting in a greenhouse, the total operating cost for the $\mathrm{R}+\mathrm{W}+\mathrm{FR}$ LEDs was calculated to be lower than that for INC and HPS lamps when various factors, such as initial purchase prices and bulb lifetime, but not installation costs, were considered (Meng, 2014). Potential adopters of these LEDs for photoperiodic lighting should perform an economic analysis considering their specific lighting needs and costs. Given our research findings, the efficacy of these LEDs on flowering should not be a factor.

\section{Literature cited}

Blanchard, M.G. and E.S. Runkle. 2009. Use of a cyclic high-pressure sodium lamp to inhibit flowering of chrysanthemum and velvet sage. Sci. Hort. 122:448454 .

Blanchard, M.G. and E.S. Runkle. 2010. Intermittent light from a rotating highpressure sodium lamp promotes flowering of long-day plants. HortScience 45:236241.

Blanchard, M.G., E.S. Runkle, and J.M. Frantz. 2011. Energy-efficient greenhouse production of Petunia and Tagetes by manipulation of temperature and photosynthetic daily light integral. Acta Hort. 893:857-864.

Craig, D.S. and E.S. Runkle. 2012. Using LEDs to quantify the effect of the red to far-red ratio of night-interruption lighting on flowering of photoperiodic crops. Acta Hort. 956:179-186.

Craig, D.S. and E.S. Runkle. 2013. A moderate to high red to far-red light ratio from light-emitting diodes controls flowering of short-day plants. J. Amer. Soc. Hort. Sci. 138:167-172.

Currey, C.J. and J.E. Erwin. 2011. Photosynthetic daily light integral impacts growth and flowering of several kalanchoe species. HortTechnology 21:98-102.

Devlin, P. 2008. Photocontrol of flowering, p. 185-210. In: G.C. Whitelam and
K.J. Halliday (eds.). Light and plant development. Blackwell Publ., Oxford, UK.

Faust, J.E., V. Holcombe, N.C. Rajapakse, and D.R. Layne. 2005. The effect of daily light integral on bedding plant growth and flowering. HortScience 40:645649.

Heo, J., C. Lee, D. Chakrabarty, and K. Paek. 2002. Growth responses of marigold and salvia bedding plants as affected by monochromic or mixture radiation provided by a light-emitting diode (LED). Plant Growth Regulat. 38:225230.

Kim, H.-H., R.D. Heins, and W.H. Carlson. 2002. Development and flowering of Petunia grown in a far-red deficient light environment. Acta Hort. 580:127-135.

Korczynski, P.C., J. Logan, and J.E. Faust. 2002. Mapping monthly distribution of daily light integrals across the contiguous United States. HortTechnology 12:12-16.

Lim, S.R., D. Kang, O.A. Ogunseitan, and J.M. Schoenung. 2012. Potential environmental impacts from the metals in incandescent, compact fluorescent lamp (CFL), and light-emitting diode (LED) bulbs. Environ. Sci. Technol. 47:1040-1047.

Meng, Q. 2014. Investigating use of blue, red, and far-red light from light-emitting diodes to regulate flowering of photoperiodic ornamental crops. Michigan State Univ., East Lansing, MS Thesis.

Morrow, R.C. 2008. LED lighting in horticulture. HortScience 43:19471950.

Nelson, J.A. and B. Bugbee. 2014. Economic analysis of greenhouse lighting: Light emitting diodes vs. high intensity discharge fixtures. PLoS One 9(6): e99010.

Nishidate, K., Y. Kanayama, M. Nishiyama, T. Yamamoto, Y. Hamaguchi, and $\mathrm{K}$. Kanahama. 2012. Far-red light supplemented with weak red light promotes flowering of Gypsophila paniculata. J. Jpn. Soc. Hort. Sci. 81:198-203.

Oh, W., I.H. Cheon, K.S. Kim, and E.S. Runkle. 2009. Photosynthetic daily light integral influences flowering time and crop characteristics of Cyclamen persicum. HortScience 44:341-344.

Padhye, S. and E. Runkle. 2009. Providing long-days with CFLs. GrowerTalks 72:58-62.

Park, Y.J., Y.J. Kim, and K.S. Kim. 2013. Vegetative growth and flowering of $\mathrm{Di}$ anthus, Zinnia, and Pelargonium as affected by night interruption at different timings. Hort. Environ. Biotechnol. $54: 236-242$.

Philips. 2014. Growing value: Philips GreenPower LED flowering lamp-100120 V. 12 Mar. 2014. <http://www. lighting.philips.com/pwc_li/main/ shared/assets/downloads/pdf/horticulture/ leaflets/cl-g-flowering_lamp-en-100120v.pdfs.

Pimputkar, S., J.S. Speck, S.P. DenBaars, and S. Nakamura. 2009. Prospects for LED lighting. Nat. Photonics 3:180182.

Runkle, E.S. and R.D. Heins. 2001. Specific functions of red, far red, and blue light in flowering and stem extension of long-day plants. J. Amer. Soc. Hort. Sci. 126:275-282.

Runkle, E.S. and R.D. Heins. 2003. Photocontrol of flowering and extension growth in the long-day plant pansy. J. Amer. Soc. Hort. Sci. 128:479-485.

Runkle, E.S., R.D. Heins, A.C. Cameron, and W.H. Carlson. 1998. Flowering of herbaceous perennials under various night interruption and cyclic lighting treatments. HortScience 33:672-677.

Runkle, E.S., S.R. Padhye, W. Oh, and K. Getter. 2012. Replacing incandescent lamps with compact fluorescent lamps may delay flowering. Sci. Hort. 143:5661 .

Sager, J.C., W.O. Smith, J.L. Edwards, and K.L. Cyr. 1988. Photosynthetic efficiency and phytochrome photoequilibria determination using spectral data. Trans. Amer. Soc. Agr. Eng. 31:1882-1889.

Sato, T., N. Kudo, T. Moriyama, H. Ohkawa, Y. Kanayama, and K. Kanahama. 2009. Acceleration of flowering of Eustoma grandiflorum in early winter by day-extension treatments with far-red rich bulb-type fluorescent lamps. Hort. Res. (Jpn.) 8:327-334.

Schamp, B., E. Pauwels, and B. Gobin. 2012. Developing LED light recipes for multi-layering systems: LED as an alternative for HPS in forcing of Rhododendron simsii. Acta Hort. 956:121-128.

Schubert, E.F. and J.K. Kim. 2005. Solidstate light sources getting smart. Science 308:1274-1278.

Shin, J.H., H.H. Jung, and K.S. Kim. 2010. Night interruption using light emitting diodes (LEDs) promotes flowering of Cyclamen persicum in winter cultivation. Hort. Environ. Biotechnol. 51:391-395.

Tähkämö, L., M. Puolakka, L. Halonen, and G. Zissis. 2012. Comparison of life cycle assessments of LED light sources. J. Light Visual Environ. 36:44-53. 
Thomas, B. and D. Vince-Prue. 1997. Photoperiodism in plants. Academic Press, San Diego, CA.

Vaid, T.M. and E.S. Runkle. 2013. Developing flowering rate models in response to mean temperature for common annual ornamental crops. Sci. Hort. 161:15-23.

Warner, R.M. 2010. Temperature and photoperiod influence flowering and morphology of four Petunia spp. HortScience 45:365-368.
Warner, R.M. and J.E. Erwin. 2005. Prolonged high temperature exposure and daily light integral impact growth and flowering of five herbaceous ornamental species. J. Amer. Soc. Hort. Sci. 130:319-325.

Whitman, C.M., R.D. Heins, A.C. Cameron, and W.H. Carlson. 1998. Lamp type and irradiance level for daylength extensions influence flowering of Campanula carpatica 'Blue Clips', Coreopsis grandiflora 'Early Sunrise', and
Coreopsis verticillata 'Moonbeam' J. Amer. Soc. Hort. Sci. 123:802-807.

Yamada, A., T. Tanigawa, T. Suyama, T. Matsuno, and T. Kunitake. 2009. Red:farred light ratio and far-red light integral promote or retard growth and flowering in Eustoma grandiflorum (Raf.). Shinn. Scientia Hort. 120:101-106. 